\title{
Oral Health Professional Alert on Special Care Dentistry
}

Special needs dentistry, also known as special care dentistry, is a specialty of dentistry concerned with the oral health of people who have intellectual disability, or who are affected by other medical, physical, or psychiatric issues. Their additional needs may be due directly to their impairment or disability, or to some aspect of their medical history that affects their oral health, or because their social, environmental or cultural context disables them with reference to their oral health. ${ }^{1}$ According to data from the Indonesian Medical Council, there was an increasing number of Indonesians experiencing chronic diseases including cancer, stroke, heart disease, renal disease, and diabetes mellitus from 2013 to $2018 .{ }^{2}$ Unfortunately, there was no data describing other special needs condition aside from medically challenged. This absence of data might make dentists and authorities complacent about this need. Even in the developed country, we found that people with disabilities were rarely identified as a priority population group in the public health policy and practice. ${ }^{3}$

Along with increasing awareness of parents and careers, supporting facilities and education such as physiotherapy, speech therapy, management behavior are much in demand. Though, dental treatment is still not popular. They are prioritizing general health instead of dental and oral health to support short term impact. ${ }^{4}$ Meanwhile, special need persons are prone to poor oral health. People with developmental disabilities have higher rates of cavities, gum disease and tooth loss and the cause is often heartbreakingly simple. ${ }^{5}$ Many of these persons are physically unable to brush their teeth, and many won't allow someone else do it for them. ${ }^{6}$ Others are hampered by medical conditions, or by the side effects of medications they take, which is why regular dental checkups and cleanings are so important.

\section{General dentists are reluctant of taking care of special need patients}

We recognized that there are only a few oral health professions that work to improve the oral health of people with special needs. ${ }^{7}$ Not only is their access to care almost non-existent in comparison to the general population, but also the facilities are inadequate and staff lack awareness of oral health matters that may impact those with special needs. ${ }^{8}$ Moreover, parents and careers are confronted with different problems such as, dentists who lack skills and competency in managing people with disabilities. Dentists reported having difficulty treating such patients. The complexity in treating patients with special needs, the variety of medical conditions or disabilities that require more time or altered delivery methods than the routine delivery of dental care for the general population, ${ }^{9}$ and sometimes patients required special methods and techniques to treat their oral health conditions has led to low preparedness and willingness of oral health professionals to treat patients with special needs. ${ }^{10}$ It requires a holistic approach that is dentist led in order to meet the complex requirements of people with impairments. It may impact access and thus their oral health, while other complications include inconvenient locations of dental clinics, transport issues, and cost of dental treatment. ${ }^{11}$ All patients with special needs should have equal access and high-quality treatment that focuses on patient safety, patient-centered care, and treatment of all dental needs. Thus, oral health professional needs to have training or special education to handle patients with special needs in an effort to increase oral and dental health of this population.

\section{Dental student training improvement is needed}

It is written in standard competency of Indonesian dental doctor released by Indonesian Medical Council that undergraduate dental student must be able to ascertain congenital and hereditary abnormalities in oral cavity, and maintaining oral soft tissue health in patients with compromised medical condition. In fact, there are limitation of opportunity for them to meet those special patients. Dentists who treat patients with special needs are dental pediatrics; there are no dental specialists who specifically manage patients who are adults with special needs. ${ }^{12}$ Furthermore, for the undergraduate basis, dental school are not well equipped with staff and tools to support that competency. Of the 11 dental schools that have been accredited "A" in Indonesia, there are only 4 dental schools who have structured dental courses on taking care of oral and dental health for person with special needs. This program is restricted to postgraduate student only. There is no syllabus or program for undergraduate dental students. Lack of training and experience of undergraduate dental students in dealing with patients with special needs was one of the most reported issues that inhibits the treatment of these patients. Therefore, the access of dental student to gain knowledge and experience in this major should be improved.

Indeed, it is well known that good oral health is conducive to overall well-being. Due to increasing demand of treating special care persons with their complexities, oral health professionals need to improve their skill and knowledge.

\author{
Tania Saskianti, DDS, PhD, Ped Dent \\ Chairperson, Joint Scientific Meeting in Special Care Dentistry \\ Lecturer, Department of Pediatric Dentistry \\ Faculty of Dental Medicine, Universitas Airlangga
}




\section{REFERENCES}

1. Friel S, Jamieson L. Political economy, trade relations and health inequalities: lessons from general health. Community Dent Health. 2019; 36(2), 152-156 (2019).

2. National Institute of Health Research and Development of Ministry of Health Indonesia. Main Result of Basic Health Research 2018. 2018.

3. Victorian Health Promoting Foundation. Disability and health inequalities in Australia. VicHealth. 2012; 1-11.

4. Anders PL, Davis EL. Oral health of patients with intellectual disabilities: A systematic review. Spec Care Dentist. 2010; 30(3):110-7.

5. Minihan PM, Morgan JP, Park A, Yantsides KE, Nobles CJ, Finkelman MD, et al. At-home oral care for adults with developmental disabilities A survey of caregivers. J Am Dent Assoc. 2014; 145(10):1018-25.

6. Eijsink AM, Schipper G, Vermaire JH. A Q-methodology study among caregivers of people with moderate intellectual disabilities on their clients' health care: An example in oral health. J Appl Res Intellect. Disabil. 2018; 31(5):915-26.

7. Wyne AH, Hammad N, Splieth C. Oral health knowledge of health care workers in special children's center. Pak J Med Sci. 2015; 31(1):164-8.

8. Hewson ND. Submission 552 - Australian Dental Association Inc - Disability Care and Support - Public inquiry. Aust Dent Assoc. $2010 ; 1-20$.

9. Wilson NJ, Lin Z, Villarosa A, Lewis P, Philip P, Sumar B, et al. Countering the poor oral health of people with intellectual and developmental disability: a scoping literature review. BMC Public Health. 2019; 19(1):1530.

10. Alumran A, Almulhim L, Almolhim B, Bakodah S, Aldossary H, Alakrawi Z. Preparedness and willingness of dental care providers to treat patients with special needs. Clin Cosmet Investig Dent. 2018; 10:231-6.

11. Steinberg BJ. Issues and challenges in special care dentistry. J Dent Educ. 2005; 69:323-4.

12. Vertel N, Harrison RL, Campbell KM. Access to Dental Services for Children with Special Health Care Needs: A Pilot Study at the Dental Department of BC Children's Hospital. J Can Dent Assoc. 2017; 83:h6. 